CLINICAL STUDY

\title{
Continuous subcutaneous hydrocortisone infusion in Addison's disease
}

\author{
Kristian Løvås ${ }^{1,2}$ and Eystein S Husebye $\mathrm{e}^{1,2}$ \\ ${ }^{1}$ Division of Endocrinology, Institute of Medicine, University of Bergen, and ${ }^{2}$ Department of Medicine, Haukeland University Hospital, 5021 Bergen, \\ Norway \\ (Correspondence should be addressed to K Løvås; Email: kristian.lovas@med.uib.no)
}

\begin{abstract}
Objective: The conventional replacement therapy in Addison's disease (AD) does not restore the normal diurnal cortisol rhythm. We explored the feasibility and safety of continuous s.c. hydrocortisone infusion (CSHI) as a novel mode of glucocorticoid replacement therapy.

Design and methods: Seven patients with AD were treated with CSHI in an open-labelled clinical study for up to three months. Adequacy of glucocorticoid replacement was assessed by $24 \mathrm{~h}$ blood and saliva sampling in one patient and by salivary cortisol day curves in six outpatients. Subjective health status was monitored by the Short Form-36 questionnaire.

Results: CSHI re-established the circadian variation and normal levels of cortisol in the patients, with minor day-to-day variation. Most of the patients could reduce their glucocorticoid dose considerably without adverse reactions. The treatment was well tolerated and positively evaluated by the patients. Conclusions: CSHI is technically feasible and safe in patients with AD. A daily dose of $\sim 10 \mathrm{mg} / \mathrm{m}^{2}$ body surface area/day restores the circadian variation and normal levels of salivary cortisol in most patients, which is close to the estimated daily requirement. We hypothesise that selected patients will benefit from restoration of the circadian cortisol rhythm.
\end{abstract}

European Journal of Endocrinology 157 109-112

\section{Introduction}

Many patients with primary adrenal insufficiency (Addison's disease, AD) experience symptoms such as fatigue in spite of conventional replacement therapy with glucocorticoids and mineralocorticoids (1). DHEA replacement therapy in these patients has attracted much interest recently, but the importance for subjective health status is still not clear (2-5). The patients' symptoms may at least partly be due to unphysiological glucocorticoid replacement, as no current mode of replacement can restore the cortisol rhythm to normal. The conventional replacement therapy in $\mathrm{AD}$ has been oral hydrocortisone $(\mathrm{HC})$ 20-30 mg daily, equivalent to cortisone acetate (CA) 25-37.5 mg, divided into two or three doses (6). Such treatment results in periods of very high and very low cortisol levels. Furthermore, new estimates show endogenous cortisol production rates of $5.4-6.1 \mathrm{mg} / \mathrm{m}^{2}$ per day $(7,8)$, which are lower than was previously thought. The possible roles of the normal pulsatile and circadian cortisol rhythms and their relevance to the glucocorticoid replacement therapy were recently reviewed (9).

There is a remarkable paucity of studies of glucocorticoid replacement therapy in $\mathrm{AD}$, particularly when it comes to health-related quality of life. In fact, only one randomised clinical trial addressed this issue properly, which showed that dosage twice daily resulted in better subjective health scores than once daily (10). Furthermore, a few studies of the biochemical effects of glucocorticoid replacement conclude that the lowest possible dose divided into two or three doses should be given $(11,12)$. Thus, there are indications that mimicking endogenous cortisol rhythm may be beneficial for the patients.

Here, we report the results of an open-labelled feasibility study of continuous s.c. HC infusion (CSHI) in seven patients with AD.

\section{Methods}

\section{Patients and design}

Seven patients with biochemically verified $\mathrm{AD}$ gave written informed consent. The principal aim of the study was to evaluate whether CSHI is technically feasible. This included finding appropriate dosage and dosing profiles in the infusion pumps. A secondary aim was to evaluate whether such treatment was well tolerated by the patients. The study was approved by the local ethics committee.

HC (Solu-Cortef; Pfizer) of $50 \mathrm{mg} / \mathrm{ml}$ solution was loaded into a MiniMed insulin pump (model 307C or 308; Medtronic, Minneapolis, MN, USA). The infusion gear was applied as for continuous s.c. insulin infusion 
in the abdominal wall. Both the solution and the infusion set were replaced every three days.

One patient (Patient 1) entered a pilot study over three months to determine the appropriate $\mathrm{HC}$ dose for CSHI. Based on the recent estimates of endogenous cortisol production $(7,8)$ and repeated salivary cortisol sampling, an HC dose of $10 \mathrm{mg} / \mathrm{m}^{2}$ body surface area/ $24 \mathrm{~h}$ was chosen as the start dose for further studies.

To further study the physiological effects of CSHI treatment on the hypothalamic-pituitary-adrenal axis, one patient (Patient 2) was admitted for repeated blood and saliva sampling. The standard HC dosage profile based on Patient 1 is shown in Fig. 1A. Blood was drawn from an in-dwelling catheter in the cubital vein.

Five patients (Patients 3-7) were enrolled in an openlabelled clinical study of 2 weeks, with an optional extension for another 10 weeks. Patient 7 has required high doses of glucocorticoids since he was diagnosed; giving elevated cortisol levels but no clinical signs of glucocorticoid excess (i.e., no Cushingoid features, normal bone mineral density). Therefore, his start dose was increased by $50 \%$. During the first 2 weeks of the study, the $\mathrm{HC}$ replacement therapy was assessed by repeated salivary cortisol measurements at 0700, 0900, 1100, 1300,
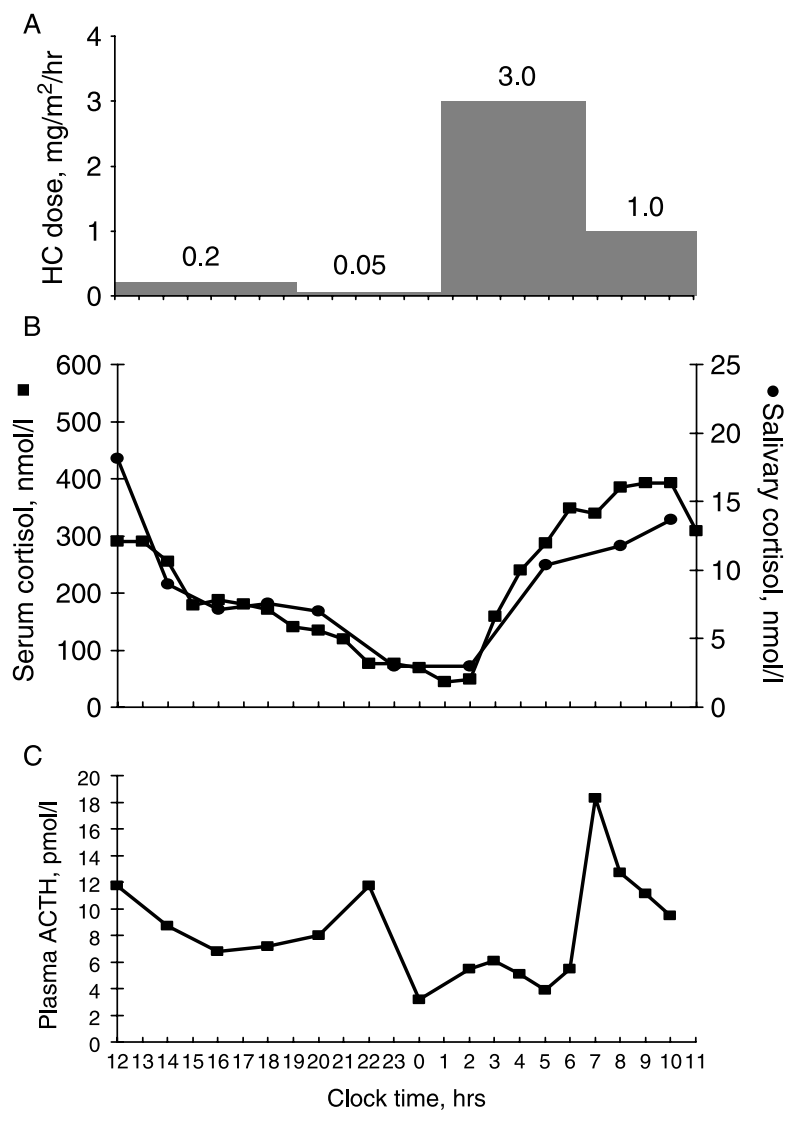

Figure 1 Re-established circadian rhythms in one patient (no. 2) with (A) standard HC start dosing schedule; (B) serum ( $\square$ ) and salivary (O) cortisol measurements and (C) plasma ACTH profile.
1900, 2100 and 2300 h on two subsequent days early in the treatment period and two subsequent days late in the treatment period. In those who continued CSHI treatment beyond two weeks, the doses were adjusted at the discretion of the investigators, aiming to obtain salivary cortisol levels within the reference limits.

\section{Measurements}

Saliva was collected by Salivette tubes (Sarstedt, Nüremberg, Germany) and posted to the laboratory. Salivary cortisol was measured by cortisol enzyme immunoassay for saliva (Diagnostics Systems Labs, Webster TX, USA) and serum cortisol and plasma adrenocorticotropin (ACTH) were measured by kits from Diagnostic Products Corp. (Los Angeles, CA, USA).

Subjective health status was monitored by the Short Form-36 (SF-36) questionnaire, which the patients completed on each visit. Adverse effects were recorded separately. Changes in SF-36 scores from baseline were analysed by paired $t$-test, and considered significant at a level of $P<0.05$. When discontinuing before 3 months, the last scores obtained were carried forward for statistical analysis.

\section{Results}

\section{Patients and treatment}

Characteristics of the patients are shown in Table 1. Patient 1 had type 1 diabetes mellitus and hypothyroidism and Patient 4 had premature ovarian failure. Fludrocortisone replacement was kept unchanged during the study. None of the patients were on DHEA treatment. Their regular doses of CA prior to the study had been based on best clinical judgment (6) and salivary cortisol measurements (13).

Figure 1 shows cortisol and ACTH levels in Patient 2 during the CSHI start dose schedule. The correlation between salivary and serum cortisol measurements was excellent. Both were within the lower range of the respective reference ranges (serum: morning 138-690 nmol/l, evening 69-345 nmol/l; saliva: given in Fig. 2). Plasma ACTH profiles throughout $24 \mathrm{~h}$ were mostly at the upper reference limits (morning $2.0-11.6 \mathrm{pmol} / \mathrm{l}$, evening $<4.9 \mathrm{pmol} / \mathrm{l}$ ), considerably lower than any ACTH measurements that have previously been measured in this patient (data not shown). The ACTH peak in the evening may relate to stressful replacement of a clotted catheter, whereas somewhat elevated ACTH levels during the night might be explained by repeated awakenings.

Figure 2 shows salivary cortisol profiles during the first 14 days of CSHI treatment of the five patients who received the fixed $\mathrm{HC}$ dose as given in Fig. 1A. Based on these measurements, minor dose adjustments were made in those who continued the trial, aiming to have their salivary 
Table 1 Patient characteristics and treatment.

\begin{tabular}{|c|c|c|c|c|c|c|c|c|c|}
\hline \multirow[b]{2}{*}{$\begin{array}{l}\text { Patient } \\
\text { no. }\end{array}$} & \multirow[b]{2}{*}{ Gender } & \multirow[b]{2}{*}{$\begin{array}{c}\text { Age } \\
\text { (years) }\end{array}$} & \multirow[b]{2}{*}{$\begin{array}{l}\text { Duration } \\
\text { of } A D \\
\text { (years) }\end{array}$} & \multirow[b]{2}{*}{$\begin{array}{l}\text { Fludrocorti- } \\
\text { sone (mg/day) }\end{array}$} & \multicolumn{5}{|c|}{ Glucocorticoid replacement } \\
\hline & & & & & & Before study (mg) & $\begin{array}{c}\mathrm{HC} \\
\text { equivalent } \\
\text { (mg/day) }\end{array}$ & $\begin{array}{c}\text { First } 2 \\
\text { weeks, } \\
\text { CSHI } \\
(\mathrm{mg} / \text { day })^{\mathrm{a}}\end{array}$ & $\begin{array}{c}12 \text { weeks, } \\
\text { CSHI } \\
(\mathrm{mg} / \text { day })^{\mathrm{b}}\end{array}$ \\
\hline 1 & $\mathrm{~F}$ & 46 & 5 & 0.10 & $\begin{array}{l}\text { CA } \\
\text { DX }\end{array}$ & $\begin{array}{l}10+5 \\
0.125\end{array}$ & 18 & 19.4 & 19.4 \\
\hline 2 & $\mathrm{~F}$ & 64 & 2 & 0.15 & $\mathrm{CA}$ & $12.5+12.5+12.5$ & 30 & 17.9 & - \\
\hline 3 & $\mathrm{~F}$ & 47 & 23 & 0.05 & $\mathrm{CA}$ & $12.5+12.5+5$ & 24 & 13.6 & 16.7 \\
\hline 4 & M & 30 & 10 & 0.10 & $\mathrm{CA}$ & $18.75+12.5+6.25$ & 30 & 23.7 & - \\
\hline 5 & $\mathrm{~F}$ & 47 & 11 & 0.10 & $\mathrm{CA}$ & $25+12.5+12.5$ & 40 & 17.9 & 12.9 \\
\hline 6 & $\mathrm{~F}$ & 35 & 1 & 0.10 & $\mathrm{CA}$ & $25+12.5+12.5$ & 40 & 22.0 & 23.7 \\
\hline 7 & $M$ & 44 & 5 & 0.15 & $\mathrm{CA}$ & $37.5+25+25+12.5$ & 80 & 30.7 & 53.5 \\
\hline
\end{tabular}

$\mathrm{CSHI}$, continuous s.c. hydrocortisone infusion; AD, Addison's disease; CA, cortisone acetate; HC, hydrocortisone; DX, dexamethasone. ${ }^{\mathrm{a}} \mathrm{HC}$ dose $10 \mathrm{mg} / \mathrm{m}^{2}$ body surface area/24 $\mathrm{h}$, dosing profile as shown in Fig. $1 \mathrm{~A}$.

${ }^{b}$ Dose adjusted after salivary cortisol measurement.

cortisol profiles within the reference range throughout the day and night. When this was achieved, the 24-h urine free cortisol levels were within normal limits (170-308 nmol/ $24 \mathrm{~h}$; reference range 70-370), and morning ACTH levels brought from high $(>39 \mathrm{pmol} / \mathrm{l})$ to near normal levels $(<18 \mathrm{pmol} / \mathrm{l})$. The patients eventually reduced their glucocorticoid doses to $40-85 \%$ when compared with estimated bioavailable cortisol from their oral CA treatment. The day-to-day variation in salivary cortisol levels within one patient was minor (data not shown).

\section{Subjective health status}

All the patients were satisfied with the treatment. No adverse effects were recorded; that is, no adrenal crises and no local reactions, such as bleeding, bruising or skin atrophy. Five patients were enrolled for the outpatient trial, four of whom continued CSHI beyond the principal study period of 14 days. Patient 3 discontinued the treatment after 14 days; although satisfied with the CSHI treatment, he considered his condition satisfactory with conventional treatment. Mean SF-36 scores of all subscales improved (data not shown), although statistically significant only for the physical functioning and vitality subscales (Fig. 3). After the study period of 3 months, Patients 5 and 7 wished to continue CSHI on a permanent basis and were allowed to do so to acquire long-term experience. At present, they have received CSHI treatment for 24 and 12 months respectively, with very positive evaluation on subjective health and no adverse events. Attempts have been made to revert them to conventional treatment with $\mathrm{CA}$ or $\mathrm{HC}$, but the patients have insisted on continuation of CSHI.

\section{Discussion}

This study indicates that CSHI is feasible and well tolerated in patients with $\mathrm{AD}$. The patients reduced their effective glucocorticoid doses without adverse reactions, tended to normalise ACTH levels and to improve the subjective health scores. Although most of these patients used higher doses of CA than are currently recommended (6), CSHI doses close to the estimated normal endogenous production were well tolerated in all but one patient. The long-term effects of glucocorticoid over-replacement on bone metabolism, cardiovascular disease and mortality are not yet known $(6,9,11,14)$. It is, however, likely that over-dosing confers increased risk in vulnerable individuals, and that minimising the doses should be an aim. Similarly, patients with congenital adrenal hyperplasia $(\mathrm{CAH})$ receive suppression treatment with long-acting glucocorticoids, which is limited by the risk of glucocorticoid over-dosage. Recently, a small clinical study found that circadian $\mathrm{HC}$ infusions in patients with $\mathrm{CAH}$ and $\mathrm{AD}$ improved biochemical control as measured by ACTH and 17-OH-progesterone (15). CSHI may be a means to

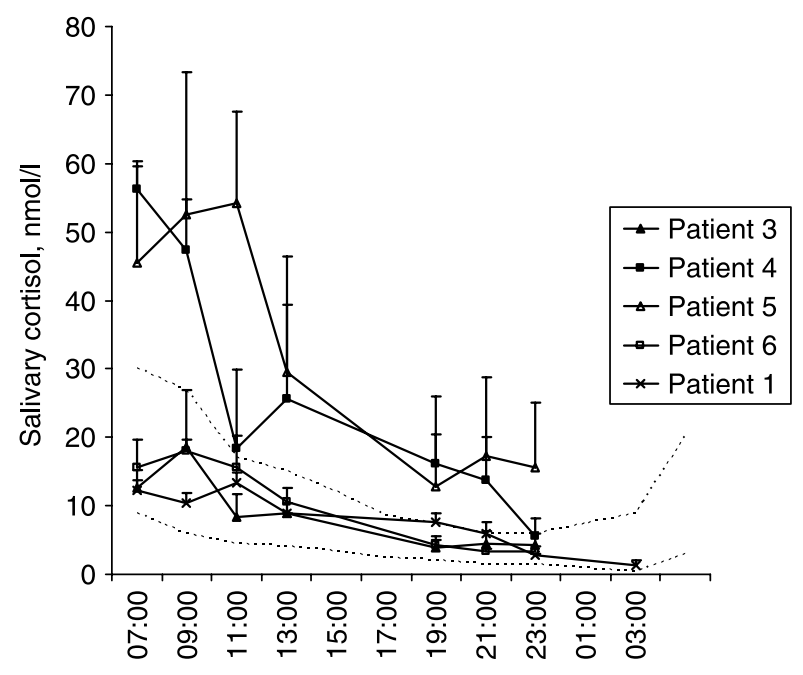

Figure 2 Salivary cortisol day-curves during the first two weeks of $\mathrm{CSHI}$ treatment in the five patients on $\mathrm{HC}$ doses as shown in Table 1. Dotted lines represent upper and lower reference limits (14). As indicated in Table 1, the $\mathrm{HC}$ dose was reduced in P4, whereas P3 discontinued the trial after two weeks. 


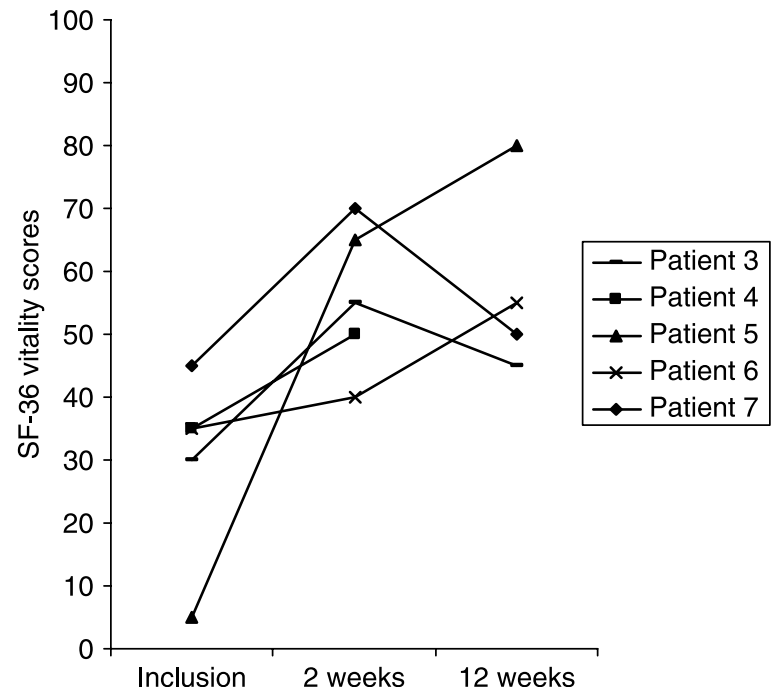

Figure 3 Short Form-36 (SF-36) vitality scores at baseline, and after 2 and 12 weeks of $\mathrm{CSHI}$ treatment.

further investigate the relevance of the circadian cortisol rhythm in CAH, especially in relation to skeletal growth, body weight and adverse effects of steroid treatment.

The effects on quality-of-life and cognition of the pulsatile and circadian variations in cortisol levels are probably under-recognised, as was recently reviewed by Crown \& Lightman (9). We found previously that patients with $\mathrm{AD}$ reported reduced general health and vitality perception when compared with the general population (1). The patients in the present study displayed a similar pattern, with an unequivocal improvement with CSHI therapy. The picture is inevitably blurred by placebo effects, but leaves a hypothesis that warrants testing in further clinical trials. If this physiological replacement concept is true, the goal should be to develop controlled-release $\mathrm{HC}$ tablets that could re-establish the circadian cortisol variation. Ultimately, a minority of patients with adrenal insufficiency or CAH might benefit from chronic CSHI therapy.

In conclusion, CSHI is technically feasible and safe in patients with AD. A daily dose of $8-15 \mathrm{mg} / \mathrm{m}^{2}$ body surface area/day restores the circadian variation and normal levels of salivary cortisol in most patients. For selected patients with poor response to conventional replacement therapy such could become a treatment option.

\section{Acknowledgements}

We are grateful to Berit Tarlebø for technical assistance with the infusion pumps, Marit M Hjelmeland for skilful laboratory assistance and Medtronic Norway for free supply of some of the infusion gear. Thanks to Haukeland University Hospital Clinical Research Facility for their kind co-operation. Grants were received from Innovest, Helse Vest, the Norwegian Medical Association and The University of Bergen.

\section{References}

1 Løvås K, Loge JH \& Husebye ES. Subjective health status in Norwegian patients with Addison's disease. Clinical Endocrinology $200256581-588$.

2 Arlt W, Callies F, van Vlijmen JC, Koehler I, Reincke M, Bidlingmaier M, Huebler D, Oettel M, Ernst M, Schulte HM \& Allolio B. Dehydroepiandrosterone replacement in women with adrenal insufficiency. New England Journal of Medicine 1999341 1013-1020.

3 Hunt PJ, Gurnell EM, Huppert FA, Richards C, Prevost AT, Wass JA, Herbert J \& Chatterjee VK. Improvement in mood and fatigue after dehydroepiandrosterone replacement in Addison's disease in a randomized, double blind trial. Journal of Clinical Endocrinology and Metabolism 200085 4650-4656.

4 Johannsson G, Burman P, Wiren L, Engstrom BE, Nilsson AG, Ottosson M, Jonsson B, Bengtsson BA \& Karlsson FA. Low dose dehydroepiandrosterone affects behavior in hypopituitary androgen-deficient women: a placebo-controlled trial. Journal of Clinical Endocrinology and Metabolism 200287 2046-2052.

5 Løvås K, Gebre-Medhin G, Trovik TS, Fougner KJ, Uhlving S, Nedrebø BG, Myking OL, Kämpe O \& Husebye ES. Replacement of dehydroepiandrosterone in adrenal failure: no benefit for subjective health status and sexuality in a 9-month, randomized, parallel group clinical trial. Journal of Clinical Endocrinology and Metabolism 200388 1112-1118.

6 Arlt W \& Allolio B. Adrenal insufficiency. Lancet $2003 \mathbf{3 6 1}$ 1881-1893.

7 Esteban NV, Loughlin T, Yergey AL, Zawadzki JK, Booth JD, Winterer JC \& Loriaux DL. Daily cortisol production rate in man determined by stable isotope dilution/mass spectrometry. Journal of Clinical Endocrinology and Metabolism 1991 72 39-45.

8 Kerrigan JR, Veldhuis JD, Leyo SA, Iranmanesh A \& Rogol AD. Estimation of daily cortisol production and clearance rates in normal pubertal males by deconvolution analysis. Journal of Clinical Endocrinology and Metabolism 199376 1505-1510.

9 Crown A \& Lightman S. Why is the management of glucocorticoid deficiency still controversial: a review of the literature. Clinical Endocrinology 200563 483-492.

10 Riedel M, Wiese A, Schurmeyer TH \& Brabant G. Quality of life in patients with Addison's disease: effects of different cortisol replacement modes. Experimental and Clinical Endocrinology 1993 $101106-111$.

11 Peacey SR, Guo CY, Robinson AM, Price A, Giles MA, Eastell R \& Weetman AP. Glucocorticoid replacement therapy: are patients over treated and does it matter? Clinical Endocrinology 199746 $255-261$.

12 Suliman AM, Freaney R, Smith TP, Mcbrinn Y, Murray B \& Mckenna TJ. The impact of different glucocorticoid replacement schedules on bone turnover and insulin sensitivity in patients with adrenal insufficiency. Clinical Endocrinology 200359 380-387.

13 Løvås K, Thorsen TE \& Husebye ES. Saliva cortisol measurement: simple and reliable assessment of the glucocorticoid replacement therapy in Addison's disease. Journal of Endocrinological Investigation $200629727-731$.

14 Howlett TA. An assessment of optimal hydrocortisone replacement therapy. Clinical Endocrinology 199746 263-268.

15 Merza Z, Rostami-Hodjegan A, Memmott A, Doane A, Ibbotson V, Newell-Price J, Tucker GT \& Ross RJ. Circadian hydrocortisone infusions in patients with adrenal insufficiency and congenital adrenal hyperplasia. Clinical Endocrinology 200665 45-50.

Received 25 January 2007

Accepted 23 April 2007 